\title{
Letter: Impact of a telemedicine-guided, population-based, STEMI network on reperfusion strategy, efficiency, and outcomes
}

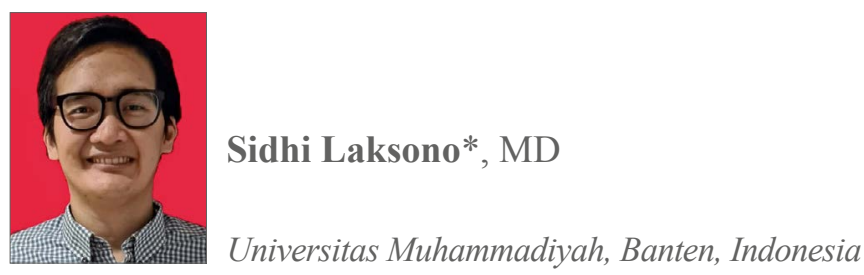

We were happy to find an interesting article by Mehta S. et al in the July 2021 volume 7, number 1 issue of AsiaIntervention on telemedicine-guided and ST-elevation myocardial infarction (STEMI) network on reperfusion strategy ${ }^{1}$. The study by Mehta et al successfully revealed increased reperfusion with percutaneous coronary intervention (PCI) and significant reduction in PCI mortality but increased cost and a non-significant reduction in mortality overall amongst all treatment pathways. As we know, telemedicine is increasingly common due to the COVID-19 pandemic and many studies have shown the usefulness of a telemedicine system for the early diagnosis of acute myocardial infarction and consequent reperfusion time reduction ${ }^{2}$.

Brazil and Colombia, like Indonesia, have poor and remote regions with no internet connection. Indonesia, an archipelago which includes over 17 thousand islands, is challenged by its geography and uneven distribution of health workers. Some areas have limited medical equipment and are several hours or days travel from the nearest capable hospital. In Indonesia, we identified the critical issues that may contribute to significant reduction of STEMI diagnosis during the pandemic such as late presentation, not going to hospital due to fear of being infected and an inadequate health system overloaded with COVID-19 cases. Tele-electrocardiography (tele-ECG) has been shown to be successful and can improve the case-resolving capacity while overcoming the geographical limitations of providing specialised healthcare ${ }^{3}$

Mehta S. et al should be congratulated on this important contribution to the understanding of the role of telemedicine, performed remotely by cardiologists who diagnose and guide the management of acute myocardial infarction.

\section{Conflict of interest statement}

The author has no conflict of interest to declare.

\section{References}

1. Mehta S, Aboushi H, Campos CM, Botelho RV, Fernandez F, Rodriguez D, Torres MA, Vieria D, Frauenfelder A, Pinto G, Lopez C, Acosta MI. Impact of a telemedicine-guided, populationbased, STEMI network on reperfusion strategy, efficiency, and outcomes. Asialntervention. 2021;7:18-26.

2. Wu J, Hall M, Dondo TB, Wilkinson C, Ludman P, DeBelder M, Fox KAA, Timmis A, Gale CP. Association between time of hospitalization with acute myocardial infarction and in-hospital mortality. Eur Heart J. 2019;40:1214-21.

3. Soriano Marcolino M, Minelli Figueira R, Pereira Afonso Dos Santos J, Silva Cardoso C, Luiz Ribeiro A, Alkmim MB. The Experience of a Sustainable Large Scale Brazilian Telehealth Network. Telemed J E Health. 2016;22:899-908. 